\title{
DRINKING WATER AND DISEASE.
}

BY PROF. W. P. MASON.

In view of Dr. Emmerich's experiments as to the effect of drinking the diluted sewage from healthy persons, there would seem to be small danger lurking in excremental material known to come from a non-pathological source.

An interesting case has recently come under my observation, which shows conclusively that even normal sewage may not be taken inwardly with impunity. Appended is the analysis of a cistern water from Albany, N. Y. The cistern is of the "filtering" typethe filtering wall being of some thickness. The property is owned and occupied by wealthy persons, and every care has been exer. cised, presumably, in keeping the premises in good order.

Suspicion was cast upon the water some months since, but its use was continued under a belief in the cleanliness of the cistern. Suddenly, with but a few hours warning, the entire household, one person excepted, were taken ill. The symptoms varied from intense nausea to great, if not dangerous, prostration. Over a month has now elapsed, yet the effects are still felt in a measure by those more severely attacked. The one person who escaped was the one who did not drink the water. Among those attacked were several children.

Upon investigation, it was found that both cistern. lining and private sewer were defective, and that more or less direct communication existed between them. $\mathrm{Cp}$ to the time of this outbreak, none of the household had suffered from diarrhcea or kindred troubles, nor could I obtain any history of recent disease of any kind. The children attacked were on a short visit only.

What I particularly desire to point out is, that the sewage, which undoubtedly caused the trouble, was normal; probably not fresh, but still normal. The absence of nitrates would go in part, moreover, to show that it was not very old.

To my mind, the evidence seems pretty clear that "specific" germs are not essential to a sewage, in order to make its presence in drinking water strongly objectionable. It is greatly to be regretted that previous analyses of the water were not made, as thereby it is possible some information might have been obtained 
as to the relation of the figures of the analysis to the "poisoning point" of the water.

\section{ANALYSIS:}

Parts per million.

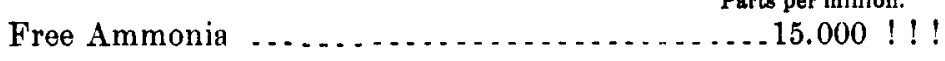

Albuminoid Ammonia. . . . . . . . . . . . . . . . 2.800

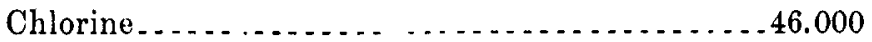

Nitrites and Nitrates... ..................... traces.

\section{AC'TION OF OFFICINAL NITRIC ACID ON SUGAR.}

BY PROF. W. P. MASON.

As every one knows, strong nitric acid acts upon sugar with production of oxalic acid.

Let us represent the reaction by the equation :

$\mathrm{C}_{12} \mathrm{H}_{22} \mathrm{O}_{11}+36 \mathrm{HNO}_{3}=6 \mathrm{H}_{2} \mathrm{C}_{2} \mathrm{O}_{4}+18 \mathrm{~N}_{2} \mathrm{O}_{4}+23 \mathrm{H}_{2} \mathrm{O}$.

Officinal nitric acid has a specific gravity of 1.068 corresponding to $11.66 \%$ pure $\mathrm{HNO}_{3}$. One hundred c.c. of such acid, acting upon sugar during a period of two days, gave no trace of oxalic acid at the end of that time. Fifteen drops of officinal acid, further diluted with water, is the maximum dose. As was to have been expected, this still weaker solution was also without action on the sugar during the stated two days time.

I mention this fact simply because it has recently come to my knowledge that a physician of this vicinity was discharged on the ground of ignorantly poisoning his patient with oxalic acid, by advising the sweetening of an ordinary dose of nitric acid. 